\title{
Histomorphological Alterations of Placenta in Normal vs Gestational Diabetes Mellitus Subjects: A Case-control Study
}

\section{ABSTRACT}

Introduction: Gestational Diabetes Mellitus (GDM) during pregnancy leads to gross and microscopic changes in the placenta. These abnormal changes in the placentas are responsible for the foetal hypoxia and increases perinatal morbidity and mortality. The study of placenta helps significantly in understanding the process of foetal development in response to various maternal conditions like GDM.

Aim: To observe the gross and microscopic changes of placenta complicated by GDM and comparing the features with normal placenta.

Materials and Methods: In this prospective case control study, performed from January 2012 to December 2015, 80 full term freshly delivered placentas were collected from the labour room with prior informed consent. Forty were from uncomplicated pregnancy (control group) and 40 were from pregnancies complicated by GDM (experimental group). Detailed gross and microscopic examinations were done on placentas from both the groups and the results were documented and associated statistically by using the Statistical Package for Social Sciences (SPSS) version 22.0.
Results: On gross examination, of 80 placentas (40 from the control group and 40 from the experimental group), those from the experimental group showed significantly higher placental weight, diameter, volume, thickness, and lower foeto-placental ratio than the control group. The $p$-value for all these parameters was observed to be $<0.0005$. Similarly, on microscopic examination villous immaturity ( $p$-value $<0.0005)$, oedema ( $p$-value $<0.0005$ ), fibrinoid degeneration ( $p$-value $<0.0005$ ), chorangiosis ( $p$-value 0.001 ) and nucleated foetal RBCs inside the capillaries ( $p$-value $<0.0005$ ) were noted to be significantly higher in the experimental group.

Conclusion: This study shows significant gross and microscopic changes in the GDM placentas, the most significant histological changes noted were the villous immaturity, thickened Basement Membrane (BM) and fibrinoid degeneration which may be attributed to impaired placental functioning and unfavourable perinatal outcomes.

\section{INTRODUCTION}

The placenta is a vital organ for the maintenance and promotion of pregnancy. The placenta also influences the effects of maternal milieu on foetus and becomes the target organ for various pathologies associated with pregnancy and one of such being the GDM [1]. GDM is a metabolic syndrome, defined as glucose intolerance with onset or first recognition during pregnancy [2]. The immediate consequence of the pregnancies complicated by GDM is increased perinatal mortality and the long-term complications are mainly attributed to the endothelial/vascular dysfunction which is associated with obesity, hypertension, type 2 diabetes mellitus, and metabolic syndrome in adult life [3-5].

The GDM during pregnancy causes gross and microscopic changes in the placenta [6]. These placentas tend to be larger, voluminous, and heavier and show numerous microscopic changes including villous oedema, immaturity and fibrinoid degeneration. These abnormal changes in the placentas are responsible for the foetal hypoxia and increases perinatal morbidity and mortality $[7,8]$. Although the placenta has been researched widely since the time immemorial, however, the exact morphological alteration of placenta in GDM is still inconsistent [9]. Therefore, this study attempted to focus on the gross and microscopic effects of GDM on placentas and compare these changes with placentas from control group.

\section{MATERIALS AND METHODS}

This prospective case-control study was conducted for a period of four years, from January 2012 to December 2015, in a tertiary referral rural hospital of central India. During the study period, 80 placentas were examined; in which 40 were from normal uncomplicated pregnancies labelled as 'Control group' and remaining 40 were from the pregnancies complicated by GDM and were labelled as 'Experimental group'. The 'Institutional Human Ethics Committee' approval was taken before starting the study (Ref: MGIMS/ RC/2013/4/12720). Informed and written consents were obtained from all the pregnant women prior to the delivery and the method of sample collection and the goal of the study were explained. GDM was diagnosed according to the International Association of Diabetes and Pregnancy Study Groups based on Hyperglycaemia and Adverse Pregnancy Outcome (HAPO) study [10].

Inclusion criteria: Those pregnancies with negative $50 \mathrm{~g}$ oral glucose tolerance test, free from any pre-existing or gestational diseases and full term deliveries (37-40 weeks) either by vaginal or caesarean section were included as control group in the study. Those diagnosed cases of GDM according to the International Association of Diabetes and Pregnancy Study Groups based on HAPO study [10], all those cases who were on treatment for GDM by insulin or diet or both and those cases having optimal glycaemic control $(\mathrm{HbA} 1 \mathrm{C}=7.0 \%)$ were included in the experimental group.

Exclusion criteria: Those cases with presence of pre-existing diabetes, hypertension, pre-eclampsia, preterm deliveries (<37 weeks), post-term deliveries ( $>40$ weeks), Intrauterine growth retardation, major congenital foetal malformation and those free from any other pre-existing or gestational diseases were excluded from the study.

\section{Preparation for Examination of Placenta}

Fresh placentas were collected immediately after delivery. The membranes were trimmed up to the margins of the placentas; 
umbilical cords were cut at about $2 \mathrm{~cm}$ from their insertions. Clots were removed. The placentas were dried with blotting paper and the following parameters were recorded: weight, volume which was determined by water displacement method and noted in $\mathrm{mL}$, placental diameter was measured by measuring tape and placental thickness at the level of insertion of cord. After gross examination, the specimens were kept for one week in 10\% formal saline for fixation and hardening to make it suitable for further routine histology processing. Three samples of at least $1 \mathrm{~cm}$ in diameter were taken from constant areas of each placenta. Sections were fixed in formalin, dehydrated in a graded ethanol series, and embedded in paraffin according to a standard protocol sections were cut at a thickness of 3-5 $\mu \mathrm{m}$ and mounted on glass slides for HaematoxylinEosin (H\&E) staining. All histological sections were reviewed by one histologist and one pathologist and both were blindfolded to the clinical data except for the gestational age.

\section{STATISTICAL ANALYSIS}

Both the groups were compared for the gross and histological features. Statistical analysis of data was done by using the SPSS version 22.0 (IBM Corp, Armonk, NY, United States). Comparisons of categorical variables between the two groups were assessed using student t-test. In all the statistical tests, a p-value $<0.05$ was considered statistically significant.

\section{RESULTS}

\section{Gross Examination}

In the control group, the mean placental weight was $450 \mathrm{~g}$ while in the experimental group it was $586 \mathrm{~g}$. Mean volume of control group was $413.5 \mathrm{~mL}$ and in the GDM group it was $578 \mathrm{~mL}$. The diameters of the placentas were measured in three axes and an average value of these diameters was taken as the exact diameter of that placenta. The mean diameter of all the placenta in the control group was $18.02 \mathrm{~cm}$ while in the GDM group mean diameter was $19.95 \mathrm{~cm}$. The mean thickness of the placenta in the control group was $1.93 \mathrm{~cm}$ and in the GDM group it was $2.38 \mathrm{~cm}$. Placentas in the GDM group were significantly heavier, larger, and thicker than the control group while a significantly lower foeto-placental ratio was observed in the GDM group compared to the control. Significant statistical differences $(p<0.005)$ were noted in all the gross parameters from both the groups [Table/Fig-1].

The mean gestational age for the experimental group was 37.9 weeks, while in the control group the mean gestational age at the time of delivery was 38.4 weeks ( $p$-value <0.005). Birth weight in the GDM group was significantly higher than the control group [Table/Fig-1]

\begin{tabular}{|c|c|c|c|c|c|c|c|}
\hline \multirow[b]{2}{*}{ Features } & \multicolumn{3}{|c|}{ Control $(n=40)$} & \multicolumn{3}{|c|}{ Experimental $(n=40)$} & \multirow{2}{*}{$\begin{array}{c}\text { p-value } \\
\text { (Student } \\
\text { t-test) }\end{array}$} \\
\hline & Max & Min & $\begin{array}{l}\text { Mean } \\
\text { (SD) }\end{array}$ & Max & Min & $\begin{array}{l}\text { Mean } \\
\text { (SD) }\end{array}$ & \\
\hline $\begin{array}{l}\text { Gestational age } \\
\text { at the time of } \\
\text { delivery (weeks) }\end{array}$ & 40 & 37 & $\begin{array}{c}38.4 \\
(1.15)\end{array}$ & 40 & 37 & $\begin{array}{l}37.9 \\
(1.05)\end{array}$ & $<0.0005$ \\
\hline $\begin{array}{l}\text { Birth weight of } \\
\text { newborn (g) }\end{array}$ & 3020 & 2200 & $\begin{array}{c}2547 \\
(217.24)\end{array}$ & 4210 & 2750 & $\begin{array}{c}3508 \\
(375.06)\end{array}$ & $<0.0005$ \\
\hline $\begin{array}{l}\text { Placental } \\
\text { weight (g) }\end{array}$ & 500 & 390 & $\begin{array}{c}450 \\
(29.43)\end{array}$ & 710 & 485 & $\begin{array}{c}586 \\
(53.56)\end{array}$ & $<0.0005$ \\
\hline $\begin{array}{l}\text { Placental } \\
\text { volume }(\mathrm{mL})\end{array}$ & 490 & 370 & $\begin{array}{l}413.5 \\
(45.71)\end{array}$ & 695 & 480 & $\begin{array}{c}578 \\
(47.11)\end{array}$ & $<0.0005$ \\
\hline $\begin{array}{l}\text { Diameter of } \\
\text { placenta }(\mathrm{cm})\end{array}$ & 21 & 16 & $\begin{array}{l}18.02 \\
(1.22)\end{array}$ & 24 & 17 & $\begin{array}{l}19.95 \\
(1.69)\end{array}$ & $<0.0005$ \\
\hline $\begin{array}{l}\text { Thickness of } \\
\text { placenta }(\mathrm{cm})\end{array}$ & 2.7 & 1.2 & $\begin{array}{l}1.93 \\
(0.4)\end{array}$ & 3.2 & 1.3 & $\begin{array}{l}2.38 \\
(0.51)\end{array}$ & $<0.0005$ \\
\hline $\begin{array}{l}\text { Foeto-placental } \\
\text { ratio }\end{array}$ & 6.19 & 5.84 & $\begin{array}{l}5.92 \\
(0.63)\end{array}$ & 6.04 & 5.69 & $\begin{array}{l}5.78 \\
(0.58)\end{array}$ & $<0.0005$ \\
\hline \multicolumn{8}{|c|}{$\begin{array}{l}\text { [Table/Fig-1]: Comparison of gross features of placenta in control and experimental } \\
\text { group (GDM). }\end{array}$} \\
\hline
\end{tabular}

\section{Histological Examination}

Sections stained with haematoxylin-eosin and light microscopy was done under different magnifications for following parameters of both the groups; immature villi, crowding of the villi and reduced intervillous space, villous oedema, fibrinoid degeneration, thickened BM, syncytial sprouts or knots, presence of cytotrophoblast, stromal cells and Hofbauer's cell, chorangiosis, nucleated foetal RBCs and infarction.

Histology of control group placenta showed normal appearing widely separated villi with maintained iinter-villous spaces and Foetal Capillaries (FC) [Table/Fig-2].

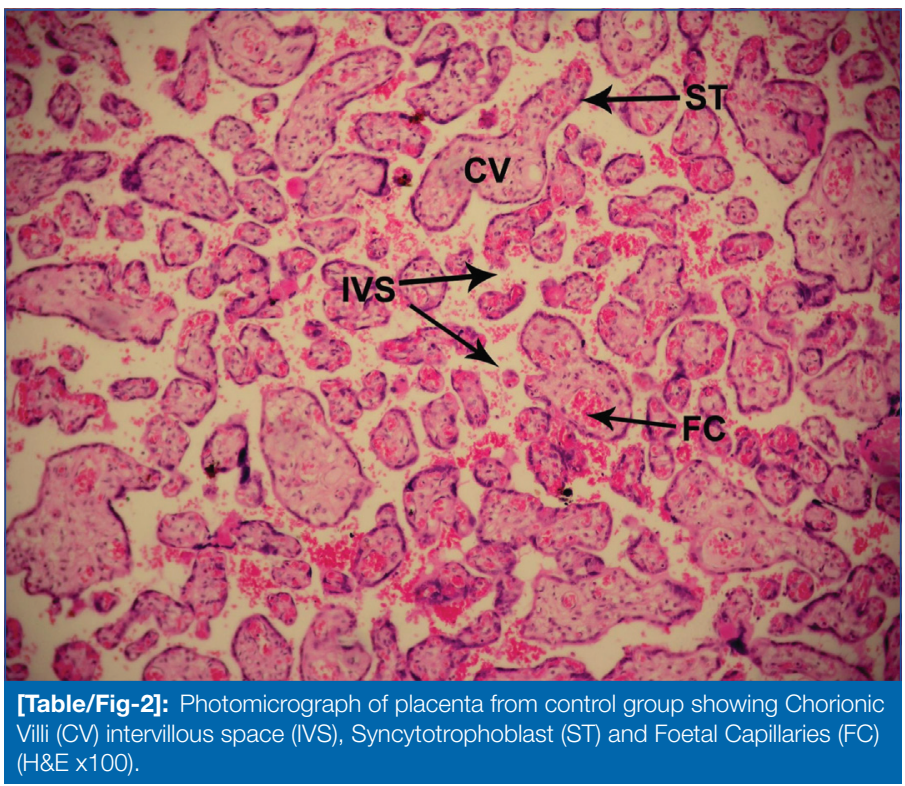

Significant structural histological differences were observed between control and experimental groups. Overcrowding of villi with diminished inter-villous space was noted in the GDM placentas in comparison to control. The central core of the villous appeared fainter than that of control group as collagen fibres were widely separated indicating oedematous villi, which is another significant finding noted in the experiment group [Table/Fig-3]. Another important noticeable feature in the GDM group was fibrinoid degeneration, which was noticed in both peri-villous and intra-villous regions as well as perivascular region [Table/Fig-3a,b]. In intra-villous fibrinoid degeneration, villi were completely occupied by fibrinoid material (resembling ghost villi) and at some places entrapped trophoblastic cells were also observed in fibrin [Table/Fig-3a]. Numerous syncytial sprouts and knots were also observed in the GDM group [Table/Fig-3c].

The terminal villi showed marked significant changes and appeared much larger in comparison to control group. The terminal villi were lined by secondary cytotrophoblasts which were seen deep to syncytiotrophoblasts in layer and at some places these cytotrophoblasts were separated from the connective tissue stroma and a well-defined thickened BM is also seen. Numerous Hofbauer cells and other stromal cells were seen in this connective tissue stroma of terminal villi [Table/Fig-4]. Chorangiosis was another remarkable feature seen in experiment group which is nothing but the presence of a large number of FC in villous stroma [Table/ Fig-5]. These FC were lined by continuous endothelium few of the FC showed Nucleated foetal Red blood cells (NFRBCs) ([Table/ Fig-5] Inset). The presence of villous immaturity and NFRBCs which indicates foetal hypoxia was significantly higher in the GDM group than the control group. Infarction where the degenerated trophoblastic cells with pyknotic nuclei were seen was the only histological finding which was not significant when compared with the control group. Detail comparison of histological examination of control and experimental group is shown in [Table/Fig-6]. 

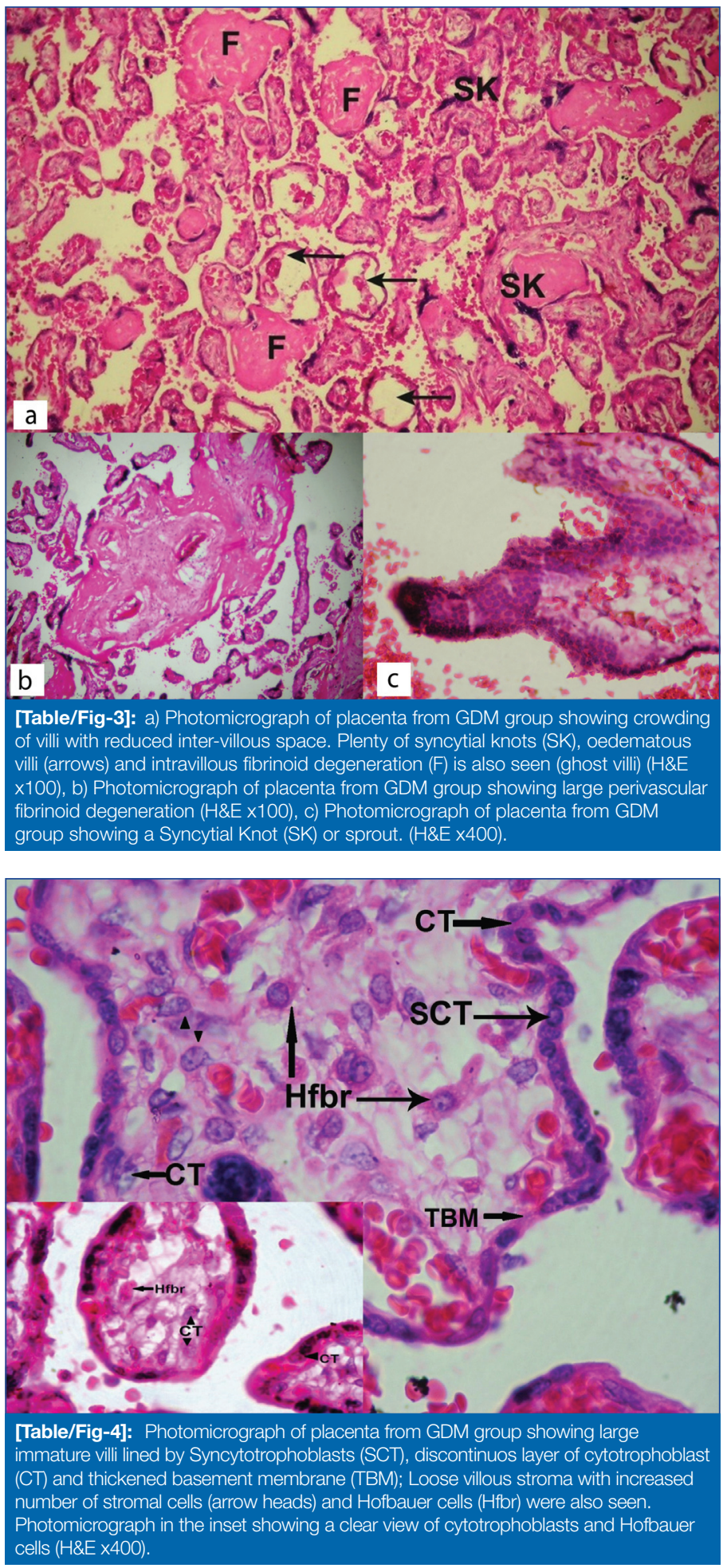

\section{DISCUSSION}

The placenta is a complex organ responsible for important and critical functions during pregnancy. The study of placenta helps significantly in understanding the process of foetal development. The research on placenta started in English literature as early as in mid-1800s and the first article was published in the Journal of the British Royal Society of Medicine in 1841, where the interface between maternal-foetal circulations by microscopic examination of placental tissue was observed [11].

The GDM is reportedly associated with foetal and maternal complications and this principally depends upon the time of disruption during the placental development-early disruption leads to incomplete development of the vasculature and causes both structural and functional dysfunction while later development of an abnormal glycaemic status more likely leads to functional dysfunction of placenta [12]. It has been reported that majority of the early and late complications

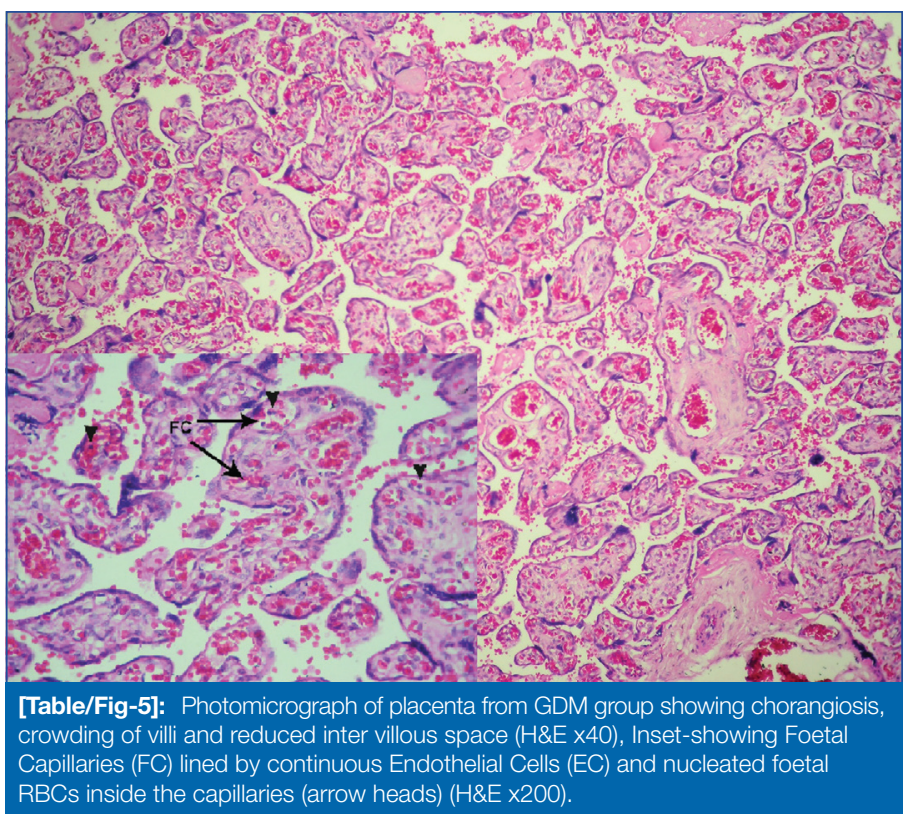

\begin{tabular}{|l|c|c|c|}
\hline Histological features & $\begin{array}{c}\text { Control group } \\
(\mathrm{n}=40)\end{array}$ & $\begin{array}{c}\text { Experimental } \\
\text { group (GDM) } \\
(\mathrm{n}=40)\end{array}$ & $\begin{array}{c}\mathrm{p} \text {-value } \\
\text { (Student } \\
\text { t-test) }\end{array}$ \\
\hline Immature terminal villi & $16(40 \%)$ & $38(95 \%)$ & $<0.0005$ \\
\hline Reduced intravillous space & $4(10 \%)$ & $30(75 \%)$ & $<0.0005$ \\
\hline Villous oedema & $9(22.5 \%)$ & $31(77.5 \%)$ & $<0.0005$ \\
\hline Fibrinoid degeneration & $15(37.5)$ & $36(90 \%)$ & $<0.0005$ \\
\hline Thickened basement membrane & $7(17.5 \%)$ & $36(90 \%)$ & $<0.0005$ \\
\hline Syncytial knots or sprouts & $19(47.5 \%)$ & $34(85 \%)$ & 0.002 \\
\hline Presence of cytotrophoblast & $3(7.5 \%)$ & $32(80 \%)$ & $<0.0005$ \\
\hline Stromal cells and Hofbauer's cell & $23(57.5 \%)$ & $34(85 \%)$ & 0.003 \\
\hline Chorangiosis & $11(27.5 \%)$ & $26(65 \% 0$ & 0.001 \\
\hline Nucleated fetal RBCs & $9(22.5 \%)$ & $24(60 \%)$ & $<0.0005$ \\
\hline Infarction & $6(15 \%)$ & $8(20 \%)$ & 0.42 \\
\hline
\end{tabular}

[Table/Fig-6]:

experimental group (GDM).

of the GDM are attributed to the aberrant placental structures and/or functions caused by the metabolic milieu of the diabetic mother. Both gross and microscopic examination of the placenta provides a unique window into the prenatal environment of the foetus and may predict the future life course of the child [13].

The weights of the placenta and the neonate at birth are often used to determine the healthy intrauterine milieu and the morphometric characteristics of the placenta may act as an indicator of in-utero foetal experience [14-17]. In this study, mean placental weight in the experiment (GDM) group was significantly higher than the control group. Several other authors also have reported a higher mean placental weight [16-18]. The other morphometric parameters like placental diameter, volume, and thickness were noted to be significantly higher in experiment group while foeto-placental ratio was significantly lower than that of control group. Similar observations have been reported by many previous authors and the findings of the present study were well correlated with a wide geographic range [Table/Fig-7] [6,7,15-21]. The placental hyperplasia in GDM might be attributed to an increase in both parenchymatous (syncytio-vascular) and non parenchymatous tissue (stroma, glycogen, lipids, tissue fluid oedema) in response to gestational diabetes. Moreover, increased placental diameter represents an increase in the placental exchange area, while increased central thickness represents an increase of trophoblastic blood vessels density in turn leads to increased placental efficiency. Some previous studies have explained these adaptive changes in placenta are in responses to the GDM $[8,9,11,22]$. 


\begin{tabular}{|c|c|c|c|c|c|c|}
\hline \multirow[b]{2}{*}{ Parameters } & \multicolumn{6}{|c|}{ Studies } \\
\hline & $\begin{array}{l}\text { Birth weight (g) } \\
\text { (p-value) }\end{array}$ & $\begin{array}{l}\text { Placental weight } \\
\text { (g) (p-value) }\end{array}$ & $\begin{array}{l}\text { Placental volume } \\
\text { (mL) (p-value) }\end{array}$ & $\begin{array}{l}\text { Placental diameter } \\
\text { (cm) (p-value) }\end{array}$ & $\begin{array}{l}\text { Placental thickness } \\
\text { (cm) (p-value) }\end{array}$ & $\begin{array}{l}\text { Foeto-placental } \\
\text { ratio ( } p \text {-value) }\end{array}$ \\
\hline Taricco E et al., [15] (2003) & $3287.1(<0.05)$ & $592.2(<0.01)$ & - & - & - & $5.69(<0.05)$ \\
\hline Daskalakis G et al., [7] (2008) & $3305.1(<0.005)$ & $734(<0.005)$ & & & & $4.13(0.03)$ \\
\hline Kucuk M and Doymaz F, [16] (2009) & $3288.3(>0.01)$ & $694.8(<0.05)$ & & & & $4.73(<0.05)$ \\
\hline Akhter F et al., [17] (2010) & - & $417.9(<0.05)$ & $415.09(<0.05)$ & $19.2(<0.05)$ & 1.33 (N.S) & - \\
\hline Saha S et al., [18] (2014) & $3900(0.001)$ & $565(0.001)$ & 487 & $16.6(0.025)$ & $3.15(0.001)$ & $5.80(0.001)$ \\
\hline Kulandaivelu AR et al., [6] (2014) & 3750 & 700 & - & 18.5 & 2.15 & 5.30 \\
\hline Gupta C et al., [19] (2015) & $2863.3(<0.05)$ & $502.7(<0.05)$ & $512(<0.05)$ & $17.4(<0.05)$ & 2.03 (N.S) & $5.69(<0.05)$ \\
\hline Ahmed TME and Halima AA, [20] (2016) & $3890(<0.05)$ & $678(<0.05)$ & - & $18.25(<0.05)$ & $2.66(<0.05)$ & - \\
\hline El Sawy NA et al., [21] (2018) & - & $593.1(<0.001)$ & - & $16.93(<0.001)$ & $3.01(<0.001)$ & - \\
\hline Present study (2021) & $3508(<0.005)$ & $586(<0.005)$ & $578(<0.005)$ & $19.95(<0.005)$ & $2.38(<0.005)$ & $5.78(<0.005)$ \\
\hline
\end{tabular}

The mean birth weight of newborns in the experiment group $(3508 \pm 375.06 \mathrm{~g})$ was observed to be significantly higher than that of control group (2547 $\pm 217.24 \mathrm{~g}$ ), this is in accordance with various previous studies [Table/Fig-3]. This macrosomia could be attributed to maternal hyperglycaemia causing foetal hyperglycaemia which in turn produces foetal hyperinsulinemia with inability to down-regulate insulin receptors. This leads to elevated anabolic action of insulin resulting in increased glycogenesis, visceromegaly and increased triglyceride synthesis with consequent obesity in the newborn [23].

In the present study, along with the gross examinations, histological examination of placentas was also carried out to observe and report the widest range of microscopic findings noted over the time in the previous literature [7-9,18]. While there are numerous studies documenting the important microscopic changes in the placentas from GDM, the exact morphology remains an object of controversy $[9,20]$. However, Kadivar $M$ et al., have claimed that the placenta from diabetic women did not show any significant microscopic findings [24] while Makhseed $M$ et al., have reported that there were no significant differences in the microscopic findings in the different groups according to the White's classification of GDM [25]. Although, Verma $R$ et al., have observed the numerous changes in GDM placentas but failed to conclude on any significant changes associated with GDM [26].

Several significant histological changes were observed in the experiment group that included villous immaturity, BM thickening, villous oedema, fibrinoid degeneration and chorangiosis. Previous studies have noted that these changes may alter the maternofoetal milieu and could affect the gaseous exchange and hamper the delivery of essential nutrient which in turn may lead to foetal complications or at the extreme intrauterine death [22,23]. Villous immaturity is defined when there is a reduced number of terminal villi and presence of a large number of immature intermediate villi with respect to the gestational age. It is characterised by the presence of loose reticular stroma with Hofbauer cells. This is one of the most frequently encountered histological findings reported in the placenta of the GDM. Villous immaturity was reported in 95\% of cases of GDM placentas of this study while Tewari $\vee$ et al., and Gheorman $L$ et al., reported in all the cases of GDM $[27,28]$ and Daskalakis $G$ et al., reported it one of the most significant finding associated with GDM [7]. Other findings denoting villous immaturity were an excessive number of syncytial sprouts or knots and the presence of cytotrophoblasts which is usually a feature of villi of early pregnancy. The syncytial sprouting along with the cytotrophobalsts increase the distance between maternal and foetal circulation and may lead to foetal hypoxia and other perinatal complications [29].

The BM thickening was another microscopic finding which is noted in significantly higher in GDM placentas. In 1976, Jones CJ and Fox $\mathrm{H}$ reported the $\mathrm{BM}$ thickening and noted that it was not due to the immune complex deposit [30]. Recent data emphasised that the BM thickening is due to the mucopolysaccharide and glycogen deposit and it is attributed to the impaired trophoblastic activity and show direct correlation with glycaemic control. The BM thickness also reduces the specific diffusing capacity of the villous membrane and contributes to the foetal hypoxia and increased foetal and neonatal morbidity associated with diabetes. This finding is in agreement with the previous studies [27-29]. Another remarkable feature in the GDM placenta was the presence of extensive fibrinoid degeneration. Fibrin deposition in placentas is distinguished by two types of deposition, perivillous and intravillous. In intravillous fibrin deposition, villi lost its architecture and known as ghost villi. In the present study, we encountered both types of fibrinoid degeneration. Excessive fibrinoid degeneration is a pathological phenomenon and attributed to be associated with abnormal foetal development [27-29].

The villous oedema was also seen in significantly higher numbers in the GDM placentas. The oedema was marked but was not sufficiently severe to be labeled the villi as hydropic. Villous oedema in the GDM is considered an important pathological event and one of the causes for foetal ischaemia [29]. Previous studies have concluded that villous oedema is mainly due to hyaluronic acid deposition inside the villi $[27,28]$. Another striking finding noted in the villi was presence of high numbers of Hofbauer cells in the GDM group which is an indicator of villous immaturity, Rudge MV et al., and Verma $\mathrm{R}$ et al., have also reported higher numbers of Hofbauer cells in the GDM placentas $[8,26]$.

The overcrowding of villi and reduced inter-villous space was also noticed significantly higher in the GDM group than the control. These findings are in accordance with Tewari $V$ et al., and llie $R$ et al., [27,31]. Overcrowding and reduce inter-villous space along with villous immaturity and oedema denote an actual consequence of metabolic disturbances associated with GDM, which results in foetal hypoxia [32]. In the present study, chorangiosis was another important histological finding noticed in the GDM placentas. Chorangiosis is defined as vascular hyperplasia of the Chorionic Villi (CV) defined as the occurrence of 10 or more villi with 10 or more capillaries in 10 or lower microscopic fields [7]. In this study, on an average of more than 12 capillaries per villi were observed and majority of them were dilated and congested. The experiment group showed a high incidence of pathological vascular changes and these changes can alter the morphology and numbers of placental vessels which is further supported by presence of chorangiosis. Several studies have reported chorangiosis as an indicator of chronic hypoxia in GDM placenta [7,8,28,33]. The presence of nucleated foetal RBCs was another indicator of chronic foetal hypoxia and seen significantly higher in cases of GDM than control, similar findings were also noted by various previous authors [34,35]. Hyperglycaemia (maternal and foetal) is a potent pro-angiogenic and pro-inflammatory agent which can impact several effects on placental vasculature such as villous immaturity, excessive syncytial sprouting, chroangiosis, fibrinoid necrosis and thickened BM. These 


\begin{tabular}{|c|c|c|c|c|c|c|c|}
\hline \multirow[b]{2}{*}{ Parameters } & \multicolumn{7}{|c|}{ Studies } \\
\hline & Villous immaturity & Crowding of Villi & Villous oedema & Thickened BM & Fibrinoid degeneration & Chorangiosis & NFRBCs \\
\hline Daskalakis G et al., [7] (2008) & $80 \%$ & - & - & - & $82 \%$ & $40 \%$ & $55 \%$ \\
\hline Tewari V et al., [27] (2011) & - & $100 \%$ & $100 \%$ & $100 \%$ & $100 \%$ & - & - \\
\hline Gheorman L et al., [28] (2012) & - & $100 \%$ & $100 \%$ & $100 \%$ & $100 \%$ & - & - \\
\hline Memon S et al., [34] (2015) & $100 \%$ & $100 \%$ & - & - & $100 \%$ & - & $100 \%$ \\
\hline Augustin G et al., [35] (2016) & $56 \%$ & - & & $50 \%$ & $46 \%$ & $46 \%$ & - \\
\hline Present study & $95 \%$ & $75 \%$ & $77 \%$ & $90 \%$ & $90 \%$ & $65 \%$ & $60 \%$ \\
\hline
\end{tabular}

microvascular changes lead to reduced vasculo-syncytial formation which is the most important cause of foetal hypoxia and increased foetal complications in GDM $[35,36]$. The detailed comparison of microscopic findings with various previous authors is illustrated in [Table/Fig-8] [7,27,28,34,35].

This was a comprehensive study on the morphological alteration of placenta in GDM, which is mainly attributed to the analysis of both gross and histological findings in detail with an elaborative discussion of histological changes in the placenta from the experimental group, and their comparison with the previous nationally and internationally available literature.

\section{Limitation(s)}

Small sample size and the selection of samples from a single tertiary care hospital which might limit the representation of the findings to the general population in a broader perspective.

\section{CONCLUSION(S)}

The present study significantly supports the relationship between placental morphology and GDM. Despite having a good glycaemic control in the experiment group, significant gross and microscopic changes were noted in the placenta. The most significant gross changes noted in the experiment group were the increased placental dimensions and low foeto-placental ratio, while the significant histological changes noted were the villous immaturity, thickened BM and fibrinoid degeneration. The gross examination of the placenta is particularly important in a set-up where nil or minimal diagnostic modalities are available or in cases where mothers land into the hospitals without any prior investigations. Further research on the topic is strongly recommended.

\section{Acknowledgement}

The author is thankful to Dr. Irfan Altaf Ansari, Associate Professor, Department of Pathology, College of Medicine, Taibah University, Madinah, Saudi Arabia, for his tireless efforts in reviewing the histology slides for his expert opinion.

\section{REFERENCES}

[1] Carrasco-Wong I, Moller A, Giachini FR, Lima W, Toledo F, Stojanova J, et al. Placental structure in gestational diabetes mellitus. Biochim Biophys Acta Mol Basis Dis. 2020;1866(2):165535.

[2] Gabbay-Benziv R, Baschat AA. Gestational diabetes as one of the "great obstetrical syndromes"--the maternal, placental, and fetal dialog. Best Pract Res Clin Obstet Gynaecol. 2015;29(2):150-55

[3] Chen L, Mayo R, Chatry A, Hu G. Gestational diabetes mellitus: its epidemiology and implication beyond pregnancy. Curr Epidemiol Rep. 2016;3:01-11. https:// doi.org/10.1007/s40471-016-0063-y.

[4] Mitanchez D, Yzydorczyk C, Simeoni U. What neonatal complications should the pediatrician be aware of in case of maternal gestational diabetes? World J Diabetes. 2015;6(5):734-43.

[5] Simeoni U, Barker DJ. Offspring of diabetic pregnancy: Long-term outcomes. Semin Fetal Neonatal Med. 2009;14(2):119-24.

[6] Kulandaivelu AR, Srinivasamurthy BC, Murugan A, Mutharasu A. Morphology and morphometric study of human placenta in rural southern India. $\mathrm{Br} \mathrm{J}$ Med Med Res. 2014;4(15):2995-3008.

[7] Daskalakis G, Marinopoulos S, Krielesi V, Papapanagiotou A, Papantoniou N, Mesogitis S, et al. Placental pathology in women with gestational diabetes. Acta Obstet Gynecol Scand. 2008;87(4):403-07.
[8] Rudge MV, Lima CP, Damasceno DC, Sinzato YK, Napoli G, Rudge CV, et al. Histopathological placental lesions in mild gestational hyperglycemic and diabetic women. Diabetol Metab Syndr. 2011;3(1):19-24.

[9] Huynh J, Dawson D, Roberts D, Bentley-Lewis R. A systematic review of placental pathology in maternal diabetes mellitus. Placenta. 2015;36(2):101-14.

[10] Coustan DR, Lowe LP, Metzger BE, Dyer AR; International Association of Diabetes and Pregnancy Study Groups. The Hyperglycemia and Adverse Pregnancy Outcome (HAPO) study: Paving the way for new diagnostic criteria for gestational diabetes mellitus. Am J Obstet Gynecol. 2010;202(6):654.e1-6.

[11] Ryan JG, Davis RK, Bloch JR. The placenta as a research biospecimen. J Obste Gynecol Neonatal Nurs. 2012;41(6):834-45.

[12] Bartha JL, Martinez-Del-Fresno P, Comino-Delgado R. Gestational diabetes mellitus diagnosed during early pregnancy. Am J Obstet Gynecol. 2000;182(2):346-50.

[13] O'Connor TG, Miller RK, Salafia C. Placental Studies for Child Development. Child Dev Perspect. 2019;13(3):193-98.

[14] Salafia CM, Zhang J, Charles AK, Bresnahan M, Shrout P, Sun W, et al Placental characteristics and birthweight. Paediatr Perinatal Epidemiol. 2008;22(3):229-39.

[15] Taricco E, Radaelli T, De Santis MN, Cetin I. Foetal and placental weights in relation to maternal characteristics in gestational diabetes. Placenta. 2003;24(4):343-47.

[16] Kucuk M, Doymaz F. Placental weight and placental weight-to-birth weight ratio are increased in diet-and exercise-treated gestational diabetes mellitus subjects but not in subjects with one abnormal value on 100-g oral glucose tolerance test. J Diabetes Complications. 2009;23(1):25-31.

[17] Akhter F, Banu M, Ferdausi R. Effect of gestational diabetes mellitus on gross morphological structure of preterm placenta. BJA [Internet]. 2010;8(1):34-38. Available from: https://www.banglajol.info/index.php/BJA/article/view/6107.

[18] Saha S, Biswas S, Mitra D, Adhikari A, Saha C. Histologic and morphometric study of human placenta in gestational diabetes mellitus. Ital J Anat Embryol. 2014;119(1):01-09.

[19] Gupta C, Harode HA, D'souza AS, Sharma A. A morphological and morphometric study of placenta with its clinical implications. Trop J Med Res. 2015;18(2):85-88

[20] Ahmed TME, Halima AA. Effect of gestational diabetes on gross morphology, histology and histochemistry of human placenta. Endocrinol Metab Syndr. 2016;5(5):01-03

[21] El Sawy NA, lqbal MS, Alkushi AG. Histomorphological study of placenta in gestational diabetes mellitus. Int J Morphol. 2018;36(2):687-92.

[22] Myatt L. Placental adaptive responses and fetal programming. J Physiol. 2006;572(1):25-30.

[23] Yang Y, Wang Z, Mo M, Muyiduli X, Wang S, Li M, et al. The association of gestational diabetes mellitus with fetal birth weight. J Diabetes Complications. 2018;32(7):635-42.

[24] Kadivar M, Khamseh ME, Malek M, Khajavi A, Noohi AH, Najafi L. Histomorphological changes of the placenta and umbilical cord in pregnancies complicated by gestational diabetes mellitus. Placenta. 2020;97:71-78. Doi: 10.1016/j.placenta.2020.06.018.

[25] Makhseed M, Musini VM, Ahmed MA, Al-Harmi J. Placental pathology in relation to the White's classification of diabetes mellitus. Arch Gynecology Obstet. 2002;266(3):136-40.

[26] Verma R, Mishra S, Kaul JM. Cellular changes in the placenta in pregnancies complicated with diabetes. Int J Morphol. 2010;28(1):259-64.

[27] Tewari V, Tewari A, Bhardwaj N. Histological and histochemical changes in placenta of diabetic pregnant females and its comparision with normal placenta. Asian Pac J Trop Dis. 2011;1(1):01-04

[28] Gheorman L, Plesea IE, Gheorman V, Histopathological considerations of placenta in pregnancy with diabetes. Rom J Morphol Embryol. 2012;53(2):329-36.

[29] Treesh SA, Khair NS. Histological changes of the human placenta in pregnancies complicated with diabetes. J Cytol Histol. 2015;6(2):01-07.

[30] Jones CJ, Fox H. An ultrastructural and ultrahistochemical study of the placenta of the diabetic woman. J Pathol. 1976;119(2):91-99.

[31] Ilie R, llie C, Enatescu I, Craina M, Nyiredi A, Heredea R. Histological fetoplacental interface changes in the gestational diabetes mellitus. Jurnalu Pediatrului. 2012;15:64-68

[32] Verma R, Mishra S, Kaul JM. Ultrastructural changes in the placental membrane in pregnancies associated with diabetes. Int $\mathrm{J}$ Morphol. 2011;29(4):1398-407. 
[33] Bentley-Lewis R, Dawson DL, Wenger JB, Thadani RI, Roberts DJ. Placental histomorphometry in gestational diabetes mellitus. American Journal of Clinical Pathology. 2014;141(4):587-92.

[34] Memon S, Goswami P, Lata H. Gross and histological alteration in the placenta of mothers suffering from gestational diabetes. J Liaquat Uni Med Health Sci. 2015;14(01):16-20.
[35] Augustine G, Pulikkathodi M, Renjith S, Jithesh TK. A study of placenta histological changes in gestational diabetes mellitus on account of feta hypoxia. International Journal of Medical Science and Public Health. 2016;5(12):2457-60.

[36] Leach L, Taylor A, Sciota F. Vascular dysfunction in the diabetic placenta-causes and consequences. J Anat. 2009;215(1):69-76.

PARTICULARS OF CONTRIBUTORS:

1. Assistant Professor, Department of Anatomy, College of Medicine, Taibah University, Al-Madinah Al-Monawarah, Madinah, Saudi Arabia.

\section{NAME, ADDRESS, E-MAIL ID OF THE CORRESPONDING AUTHOR}

Dr. Shabina Anjum,

Department of Anatomy, Taibah University, Universities Road, PO Box 344

Postal Code 42353, Al-Madinah Al-Monawarah, Madinah, Saudi Arabia.

E-mail: sjabir@taibahu.edu.sa
PLAGIARISM CHECKING METHODS: [Jain Het al.]

- Plagiarism X-checker: Feb 01, 2021

- Manual Googling: May 29, 2021

- iThenticate Software: Jul 13, 2021 (14\%)

\section{AUTHOR DECLARATION:}

- Financial or Other Competing Interests: None

- Was Ethics Committee Approval obtained for this study? Yes

- Was informed consent obtained from the subjects involved in the study? Yes

- For any images presented appropriate consent has been obtained from the subjects. No

Date of Submission: Jan 30, 2021

Date of Peer Review: Apr 29, 2021

Date of Acceptance: May 29, 2021

Date of Publishing: Oct 01, 2021 